Arteterapia. Papeles de arteterapia y educación para inclusión social ISSN-e 1988-8309

http://dx.doi.org/10.5209/ARTE.60726

\title{
"Cuando no hay caso". Las dificultades en la relación terapéutica en una intervención a través del arteterapia con una paciente pediátrica de hemodiálisis
}

\author{
Carolina Peral Jiménez ${ }^{1}$
}

Recibido: 23 de junio de 2018 / Aceptado: 23 de agosto de 2018

Resumen. Uno de los grupos del proyecto "ALETHEIA: las artes y el arteterapia como abordaje del trauma y la memoria emocional" se centra en investigar como el arteterapia puede mejorar el bienestar de los niños y las niñas en el ámbito hospitalario. Para los pacientes de pediatría la enfermedad y las experiencias médicas pueden ser vividas como una experiencia traumática, que tendrá consecuencias en su desarrollo emocional.

En este artículo no se aborda la totalidad de la investigación, sino las dificultades en la relación terapéutica surgidas en una intervención con una paciente pediátrica de hemodiálisis. El artículo se narra en primera persona en forma de relato autoetnográfico y se centra en la contratransferencia vivida por la arteterapeuta, con el propósito de mostrar las dificultades y errores surgidos en el proceso, visibilizando así la realidad del trabajo y la complejidad de los casos de trauma.

Palabras clave: arteterapia; hemodiálisis pediátrica; trauma; apego; transferencia; contratransferencia; autoetnografía

\section{[en] "When there is no case". The difficulties in the therapeutic relationship in an intervention through art therapy with a pediatric hemodialysis patient}

\begin{abstract}
One of the groups of the project "ALETHEIA: Arts and Art Therapy as an approach to trauma and emotional memory" focuses on investigating how art therapy can improve the well-being of children in the hospital setting. For pediatric patients, the disease and medical experiences can be experienced as a traumatic experience, which will have consequences on their emotional development. This article does not address the whole of the research, but the difficulties in the therapeutic relationship with a pediatric hemodialysis patient. The article is narrated in the first person in the form of an autoethnographic narrative and focuses on the countertransference experienced by the art therapist, with the purpose of showing the difficulties and mistakes arising in the process, thus making visible the reality of the work and the complexity of the cases of trauma.

Keywords: art therapy; pediatric hemodialysis; trauma; attachment; transfer; countertransference; autoetnography
\end{abstract}

Sumario. 1. Introducción: el trauma médico. 2. Arteterapia y hemodiálisis infantil. 3. Marco de la intervención y metodología. 4. Cuando no hay caso. 5. Conclusiones. 6. Referencias.

1 Universidad Complutense de Madrid. Arteterapeuta, docente e investigadora contratada a través del programa de Formación de Personal Investigador (FPI) asociado al proyecto ALETHEIA.

e-mail: carolina.peral@ucm.es

2 Proyecto I+D+i de la Universidad Complutense: "ALETHEIA: LAS ARTES Y EL ARTETERAPIA COMO ABORDAJE DEL TRAUMA Y DE LA MEMORIA EMOCIONAL”, financiado por el Ministerio de Economía y Competitividad, actual Ministerio de Ciencia, Innovación y Universidades. Referencia HAR2015-69115-R. 
Cómo citar: Peral Jiménez, C. (2018). “Cuando no hay caso”. Las dificultades en la relación terapéutica en una intervención a través del arteterapia con una paciente pediátrica de hemodiálisis, en Arteterapia. Papeles de arteterapia y educación para inclusión social 13, 2018, 33-52.

\section{Introducción: el trauma médico}

Dentro del proyecto ALETHEIA: las artes y el arteterapia como abordaje del trauma y la memoria emocional, planteamos que la enfermedad y las intervenciones médicas pueden ser vividas por los pacientes de pediatría como una experiencia traumática.

Peter Levine, creador del método Somatic Experiencing® para la curación del trauma, considera que la energía acumulada y no liberada en la experiencia amenazadora es la responsable de los síntomas del estrés postraumático. Por tanto, para él, el trauma no está únicamente en el evento traumático en sí, sino en cómo la persona experimenta una vivencia que puede llegar a dejarnos abrumados y desconectados de nuestro cuerpo (Levine \& Kline, 2016). Este terapeuta, autor del libro El trauma visto por los niños utiliza el término "trauma médico" para referirse, no únicamente a enfermedades que alteran la vida, sino a todas las experiencias como hospitalizaciones, accidentes, lesiones, tratamientos invasivos, pruebas, operaciones y anestesias que pueden quedarse impregnadas en nuestro cuerpo. Durante sus años de experiencia ha tratado a muchos adultos que recordaban como algo traumático las inmovilizaciones y miedos sufridos durante intervenciones médicas en su infancia. En esta etapa, momento de gran vulnerabilidad, las experiencias traumáticas que viven los niños y las niñas hospitalizados pueden tener un impacto en su percepción de bienestar y en la manera en la que construyen su realidad (Guzmán, Torres, Plascencia, Castellanos, \& Quintanilla, 2011). Además, pueden padecer estrés relacionado con la separación de los padres durante la hospitalización, sufrir por la pérdida de control e independencia que implica la enfermedad, tener ansiedad ante los procedimientos médicos y el dolor, así como preocupaciones y miedos acerca de la muerte. Estas experiencias pueden influir en el desarrollo de los niños y las niñas y su crecimiento emocional, por eso, el apoyo de los padres o cuidadores principales es clave para regular estas emociones, ya que una atención inadecuada por su parte puede aumentar su estrés (Malchiodi, 1999).

Aunque las plantas de pediatría se han humanizado en los últimos años, aún queda mucho camino por recorrer para que se atiendan plenamente los aspectos emocionales de la experiencia hospitalaria de un paciente. El arteterapia puede ser un recurso eficaz para mejorar el bienestar psicosocial de estos niños y niñas.

\section{Arteterapia y hemodiálisis infantil}

La hemodiálisis es un tratamiento médico que se aplica en casos de insuficiencia renal, cuando los riñones han perdido la capacidad de filtrar las sustancias tóxicas del organismo. Durante la sesión de hemodiálisis, el paciente debe permanecer conectado a la máquina, donde su sangre pasa a través de un filtro para volver libre de impurezas. La duración es de unas tres o cuatro horas, debiendo hacerse varios días por semana, según cada paciente. 
Esta enfermedad y el tratamiento pueden producir un sentimiento de dependencia del equipo médico y de la máquina, así como una sensación de falta de control. Esto unido a la incertidumbre de formar parte de una lista de espera para un trasplante, produce un gran sufrimiento psíquico. Los pacientes pueden experimentar emociones como angustia, irritabilidad, sentimiento de incapacidad o miedo, llegando a generar y relaciones ambivalentes con el equipo médico (Pía, Garrido, Fuentes, Guzmán, \& Lizano, 2009).

Existen diversas experiencias publicadas en las que se ha trabajado arteterapia con pacientes dializados, tanto adultos como con población infantil. Debido a las limitaciones de este artículo no haremos una revisión profunda del estado de la cuestión, sino que extraeremos las ideas generales, objetivos y dificultades encontradas al trabajar en este contexto. En estas publicaciones (Barrantes, 2016; Johnson, 2008; Nishida \& Strobino, 2005; Schreibman, 2013, Weldt, 2003) podemos encontrar descritas características y particularidades sobre el encuadre externo. Las sesiones de arteterapia en este ámbito se llevan a cabo mientras el paciente está conectado a la máquina, lo que conlleva evidentemente la limitación de movimientos. Es fundamental tener un especial cuidado con la higiene y los materiales que utilizamos durante las sesiones. Además, los criterios médicos están por encima de nuestra intervención y debemos estar dispuestos a adaptarnos a las posibles interrupciones por la realización de las pruebas, como por ejemplo la toma de tensión durante la sesión. La falta de privacidad es otro punto a tener en cuenta ya que generalmente la sala de hemodiálisis es un espacio abierto, en el que tanto acompañantes, como el personal médico puede escuchar e incluso intervenir durante la sesión. En el caso de los menores son frecuentes las intervenciones de los padres o acompañantes, y corresponderá en cada caso valorar si se desea incorporar el trabajo con ellos en la sesión o de lo contrario establecer ciertas pautas previas para que las intervenciones tengan la mínima repercusión posible. Los cambios de horario o traslados son también frecuentes, lo que dificulta la continuidad de las sesiones.

El tiempo que dura la sesión de hemodiálisis se puede valorar como un tiempo más significativo en términos de bienestar y salud psicológica cuando se realizan las sesiones de arteterapia, ya que proporciona un espacio para comunicar sentimientos y deseos (Nishida \& Strobino, 2005). Sin duda, para niñas y niños enfermos y hospitalizados, el arte les puede otorgar un rol activo en el que se les permite construir, destruir, decidir, cortar, pegar, etc. Frente a la pasividad y falta de control sobre las intervenciones y tratamientos médicos, los menores se convierten en una parte activa de su mejoría. Fomentar la resolución de problemas, ayudar a desarrollar la confianza en sus habilidades para tomar decisiones y mejorar la sensación de control sobre los acontecimientos de la vida, se traduce en una sensación de bienestar a pesar de la enfermedad (Malchiodi, 1999).

\section{Marco de la intervención y metodología}

Para llevar a cabo el proyecto se entró en contacto con uno de los hospitales de referencia de Madrid. El equipo médico nos propuso intervenir con dos jóvenes que asistían a hemodiálisis en horario de tarde y se establecieron una serie de reuniones para informar sobre la evolución de los casos. Así mismo se les propuso a las menores su participación en el taller y en la investigación y se entregaron a los familiares 
los documentos de consentimiento de participación y utilización de las imágenes con fines académicos, informándoles de la posibilidad de abandonar la investigación en el momento que así lo manifestaran.

Dentro del proyecto se apuesta por una metodología de investigación cualitativa, con especial énfasis en la investigación narrativa. En este artículo no se aborda la totalidad de la investigación, sino parte de una experiencia en la que se ha utilizado la autoetnografía por ser un método narrativo y subjetivo, adecuado para la reflexión personal. Santos (2013) plantea que la autoetnografía puede ser un método adecuado para la investigación del proceso arteterapéutico y para la autocomprensión, poniendo el foco en nosotros mismos, pero en relación con los otros. El objetivo de la autoetnografía no es únicamente documentar una experiencia personal, sino contribuir a generar conocimiento. Un conocimiento que está totalmente entrelazado con la experiencia personal y las vidas concretas "hasta el punto de que el conocimiento en sí, no deja de ser una narración más que participa en el mundo de las narraciones sobre la vida" (Feliu \& Lajeunesse, 2007, p. 267).

Como instrumentos de observación y recogida de datos se utilizaron la observación participante, el registro fotográfico y el diario de campo, que se completaba inmediatamente después de realizar la intervención con la finalidad de anotar todos los detalles significativos de la sesión.

Entre los objetivos generales de la investigación ALETHEIA se encuentra obtener conclusiones sobre la efectividad de la metodología de intervención utilizada en los talleres y su posible transferibilidad. Inicialmente en esta intervención se planteó seguir una de las líneas de trabajo del proyecto, centrada en la narración y la creación de historias autobiográficas, con el objetivo de lograr una historia coherente que ayude a resignificar y reestructurar las experiencias traumáticas (Van der Kolk, 2015). En todas las culturas, la narración nos sirve para organizar las experiencias vividas, construyendo una historia que posibilita dar significado a las experiencias difíciles. Se trata no tanto de la naturaleza de lo vivido, sino del el relato que prevalece a la hora de asignar significados a los sucesos vividos y dar sentido a nuestra experiencia (Payne, 2002). En el caso de los niños y niñas hospitalizados, la trama narrativa está llena de experiencias traumáticas producto de la enfermedad y el internamiento, y tiene una lógica en función del impacto que provoca en la vida del menor hasta el grado de transformarla totalmente (Guzmán Sandoval et al., 2011, p. 31).

Durante el diseño de la intervención se establecieron una serie de objetivos terapéuticos previos inspirados en la revisión de la literatura:

- Generar un espacio creativo para otorgar un rol activo a las participantes durante la sesión de hemodiálisis

- Ofrecer un espacio para la expresión de emociones relacionadas con la enfermedad

- Desarrollar habilidades de toma de decisiones mejorando así su sensación de control sobre los acontecimientos de la vida

- Utilizar técnicas narrativas para ayudar a resignificar y reestructurar la experiencia traumática

Estos objetivos se fueron reajustando durante el desarrollo del taller. 


\section{Cuando no hay caso}

Los registros, así como las emociones, reflexiones y dudas plasmadas en el diario de campo, me han servido como base para desarrollar este texto, al que he titulado "Cuando no hay caso" por la sensación de no avanzar que me ha acompañado durante el proceso, hasta el punto de llegar a afirmar que "no había caso" en más de una ocasión ${ }^{3}$. La intervención realizada ha estado marcada por una fuerte contratransferencia, que como es bien sabido es definida como "el conjunto de las reacciones inconscientes del analista frente a la persona del analizado y, especialmente, frente a la transferencia de éste" (Laplanche \& Pontalis, 2004, p. 84).

La intervención con María (nombre ficticio), tuvo lugar entre octubre de 2017 y mediados de mayo de 2018. Se realizaron un total de 17 sesiones de aproximadamente hora y media, con una frecuencia semanal. Además, se realizaron un total de 4 supervisiones durante el proceso por parte de una arteterapeuta con experiencia y en paralelo a la terapia personal de la arteterapeuta.

María tenía 12 años al inicio de la intervención arteterapéutica, cursaba $6^{\circ}$ de primaria y anteriormente había estado dos años sin acudir al colegio porque asistía al hospital por la mañana. Su tratamiento clínico de hemodiálisis comenzó en 2016 y a primeros de 2018 la incluyeron en la lista de espera para un trasplante doble, hepático y renal. El equipo médico la definió como una niña difícil, con una situación familiar complicada, ya que su madre estaba ausente y vivía con su padre y su tío, ambos en paro. En las sesiones de hemodiálisis de la mañana en la que coincidía con otros niños y niñas se solía mostrar muy disruptiva, pero la incorporación a su centro educativo habitual y el cambio al turno de tarde habían supuesto una mejoría en su comportamiento.

\subsection{Primera fase: el establecimiento del vínculo}

En la primera sesión, al verme llegar con la bata rosa de arteterapeuta, María enseguida exclamó: ¡Qué bien! ;Arteterapia!. Tras mi presentación, la explicación del proyecto y el establecimiento de las normas básicas en nuestro acuerdo, le propuse que se presentase a través de un dibujo. Primero pintó directamente con témpera una figura pequeña que dijo que era ella misma, después el paisaje y por último una figura más grande. Lo tituló "Carol y yo en un bosque" (Ver figura 1).

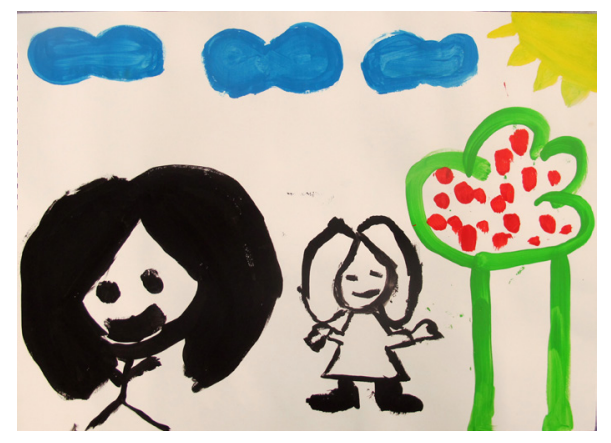

Figura 1. "Carol y yo en un bosque" (sesión nº1)

En este texto se utilizará la cursiva para referirse a trozos de conversaciones registradas en el cuaderno de campo, declaraciones de la paciente o pensamientos de la arteterapeuta. 
El hecho de que me incluyera en su primer dibujo me pareció algo positivo, un buen comienzo para establecer un vínculo sólido. Consciente de la importancia de la creación del espacio de seguridad y de una buena relación terapéutica, las primeras sesiones se centraron en trabajar estos aspectos a través de diferentes materiales y propuestas muy flexibles. Las dos semanas siguientes transcurrieron con normalidad, pero un festivo y un fuerte catarro mío, hicieron que nuestro siguiente encuentro se distanciase. Después de dos semanas sin vernos su recibimiento fue frío. En esta cuarta sesión le propuse el juego de "Si yo fuera..."4 utilizando para ello imágenes de revistas obtenidas principalmente de un catálogo de muebles que ella misma eligió. De todas las imágenes, seleccionó unos cojines porque le parecieron bonitos y porque los relacionaba con el descanso, pues declaró que le "gustaba estar sin hacer nada". Además, comentó que también podía ser dulce y blandita como un cojín, pero que cuando se enfadada era otra cosa, refiriéndose a la imagen de un cactus que había situado en el centro de su obra (Ver figura 2). También añadió que era muy cabezota, que le costaba pedir perdón y que cuando se enfadaba dejaba de hablar. Con su título "Así soy de buenas, así soy de malas", me anunciaba lo que vendría después.

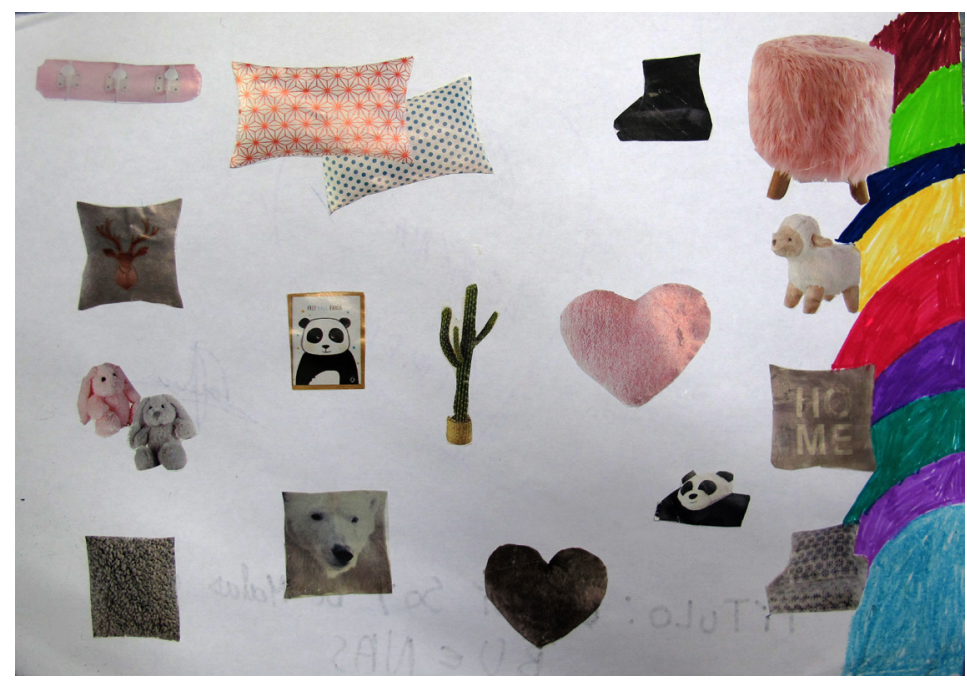

Figura 2. "Así soy de buenas, así soy de malas"

El vínculo se fue estableciendo poco a poco, especialmente en la quinta sesión, en la que me pidió que le hiciera un retrato y finalmente nos hicimos un retrato la una de la otra. Al inicio de nuestras sesiones María siempre preguntaba qué íbamos a hacer. Parecía que necesitaba ciertas pautas o propuestas, pero una vez planteadas no siempre eran aceptadas. Cuando no le interesaba algo, se enfurruñaba y decía que no lo quería hacer, y esto ocurría especialmente con temas personales o relacionados con las emociones, así como en los cierres. Esto me preocupaba porque lo veía como una forma de evitación y resistencia a involucrarse personalmente en el proceso, que verbalizó por ejemplo durante la creación del collage "Así soy de buenas, así soy de malas", diciendo "esta actividad es muy rara, quiero parar".

4 Juego popular que consiste en elegir un objeto, animal u otro tipo de categoría con la que podamos identificarnos al relacionarlo con nuestras características personales. 
En la última sesión antes de Navidades quiso hacer un adorno navideño. Finalmente eligió hacer un árbol de Navidad y yo le propuse que lo completara añadiendo deseos, pero no quiso afirmando que "para qué iba a escribir los deseos. Eso lo piensa uno para uno mismo y ya está. Yo quiero un árbol de Navidad de adorno".

María tenía dificultades para compartir sus pensamientos y emociones, y necesitaba controlar la situación en todo momento, evitando entrar en algo que quizás no pudiera llegar a entender o manejar. De hecho, esta necesidad de control no se ceñía únicamente a la sesión de arteterapia, sino también a su propio tratamiento. Su atención periférica era siempre constante, atenta a lo que pasaba en la sala, pendiente de comentarios entre enfermeros y médicos, conversaciones entre la doctora y sus familiares o resultados de análisis. Como veíamos al principio, uno de los principales motivos de estrés en pacientes pediátricos suele ser la pérdida de independencia y control que conlleva la enfermedad (Malchiodi, 1999), por este motivo, poco a poco fueron desapareciendo las propuestas, dando paso a trabajos más libres. Aunque seguía sintiendo que en sus obras había poca implicación personal y poca elaboración, por lo tras las vacaciones de Navidad que me propuse replantear con ella los objetivos terapéuticos.

\subsection{Segunda fase: el rechazo y la contratrasferencia}

La vuelta de las vacaciones de Navidad supuso un punto de inflexión en el proceso. Como tras cada breve interrupción de nuestro ritmo en las sesiones, hubo un rechazo hacia mí, pero esta vez fue mayor. Cuando llegué no me saludó, no quería realizar ninguna actividad, sino que permaneció en la cama tumbada y mirando su móvil. Tras mi felicitación de año nuevo, y mis intentos de motivarla con alguna actividad, intenté hablarle de las diferencias entre un taller de arteterapia y otro de manualidades y le planteé que pensara sobre cuáles eran sus objetivos y propósitos en arteterapia. Su respuesta fue que estaba aburrida de hacer propósitos para el año nuevo, porque eso ya lo había hecho en el colegio y que no quería hacer nada. Entonces le dije simplemente que yo estaría allí por si quería hacer algo y esperé sentada a su lado. Durante quince largos minutos para mí siguió mirando su móvil dándome la espalda, hasta que se incorporó, me sonrió y me preguntó qué tenía que hacer.

Lo más destacable de estos propósitos (ver figura 3) es, además de su visión negativa sobre sí misma, el hecho de que recalcó que no quería hacer terapia, sólo manualidades.

Esta petición no me sorprendió, pues era algo que llevaba observando desde el inicio y que además verbalizó en una ocasión en las primeras sesiones cuando la doctora le dijo que tenía que ir por la mañana a terapia con la psicóloga del hospital, a lo que ella se opuso. ¿Por qué?, le pregunté; "porque pretenden que les cuentes tu vida y yo no quiero". Su resistencia a verbalizar en los cierres se unía a ocasiones en las que se negaba a hablar también de situaciones en apariencia cotidianas, pero que quizás para ella fueran dolorosas o tenía ganas de evitar como por ejemplo, cómo había pasado las Navidades, o cómo había celebrado su cumpleaños. Su respuesta solía ser: "todo el mundo me pregunta lo mismo, quieren saber cosas de mí y no me apetece hablar". Por mi parte, esto despertaba en mí sentimientos de frustración, pero respetaba su deseo de no querer hablar. 


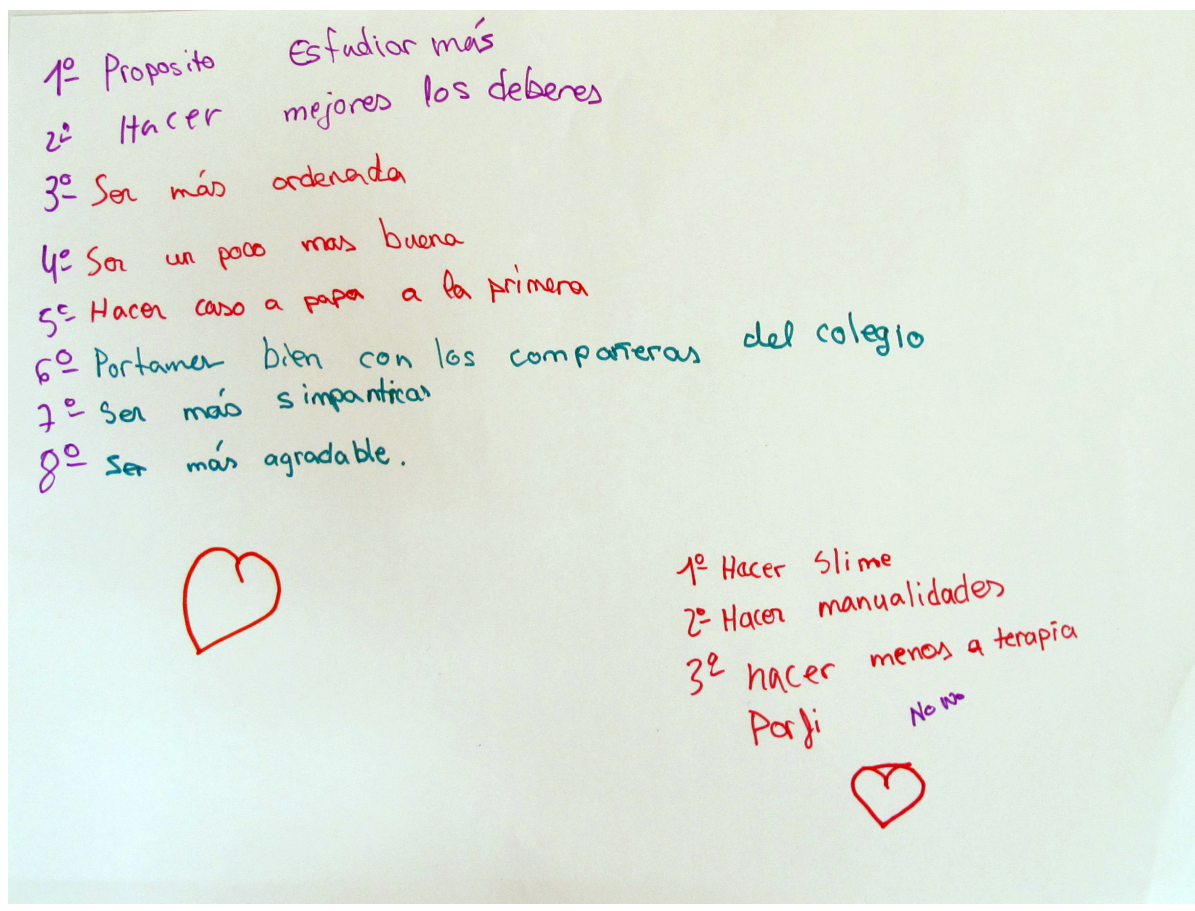

Figura 3. "Propósitos de año nuevo"

Durante las siguientes sesiones, lo que en un inicio eran simplemente recibimientos entusiastas y otros fríos, se fue convirtiendo en un día te quiero y otro día te odio. Estos rechazos eran cada vez más frecuentes, según avanzaba el vínculo, las sesiones y mi reciente embarazo, cada día más evidente. Cuando le comuniqué que estaba embarazada su reacción fue de gran sorpresa, pero una sorpresa negativa: ¿Por qué? ¿Para qué quieres un hijo si ya tienes otro? Le dije que me sorprendía su pregunta y me respondió que lo decía porque los hermanos se pelean y tienen celos. Le dije que sí, pero que los hermanos también se quieren y se protegen, ante lo que puso cara de escéptica.

Mi vida personal y en concreto la relación con mi hijo pequeño le causaba gran curiosidad; a veces me preguntaba con quién estaba mi hijo cuando yo estaba con ella o me pedía que le llevara a la sesión. También sentía curiosidad por otros aspectos cotidianos como si dormía solo o conmigo, e incluso llegó a preguntarme si yo le haría vudú porque "quería saber si era una buena madre". En una ocasión, cuando me preguntó si ya le había visto ese día me comentó "pobrecillo, te debe echar de menos". Al preguntarle por qué lo decía me respondió que porque los niños prefieren a las madres y las niñas a los padres. Afirmó que ella quería más a su padre y que por eso estaba con él, aunque ella no lo hubiera elegido. Fue la única vez que mencionó indirectamente a su madre, ya que ni siquiera en una de las sesiones en las que hicimos un mandala con el tema de la familia la incorporó o nombró. Las enfermeras me confirmaron después que nunca mencionaba a su madre y tras una reunión con la psicóloga del hospital me comunicaron que la madre estaba viva y que dejó a la niña al cuidado del padre cuando ésta tenía unos tres años, pero se desconocían los motivos. 
La historia de abandono y su actitud parecían indicar que María podría tener un apego inseguro. Consulté con la psicóloga del hospital que había tratado anteriormente a María, por si ella había realizado algún tipo de diagnóstico o si tenían una opinión sobre su estilo de apego, pero la única información que me dio fue que su intervención psicológica se limitaba a preparar a María para un posible trasplante.

La teoría del apego, desarrollada por John Bowlby (1998) establece que los cuidados recibidos en la primera infancia a través de unos cuidadores estables y disponibles son determinantes a la hora de establecer un apego sano. La vinculación con las figuras referentes permitirá al niño o la niña poseer una seguridad de base para explorar el mundo y llegar a ser una persona capaz de vincularse sanamente con los demás. Mary Ainsworth (1978) continuó con las investigaciones en ese campo y estableció tres tipos de apego: seguro, inseguro evitativo y apego inseguro ansioso -ambivalente. A partir de investigaciones posteriores se incluyó también el apego inseguro desorganizado, frecuente en la mayoría de niños maltratados.

Las dificultades de María para conectar y compartir sus emociones y sus resistencias en el proceso parecían ser compatibles con un estilo de apego inseguro evitativo. En algunas ocasiones María llegaba a expresar algunas emociones relacionadas con la enfermedad, como en una ocasión en la que comentó "no va nada bien, ni mis riñones, ni mi hígado, nada". Pero a partir de ahí el diálogo se detenía, ¿Pero por qué tenemos que hablar de esto?

Las personas con apego evitativo suelen tener muchas dificultades para hablar sobre las personas importantes en su vida, situaciones difíciles, sentimientos o emociones. Debido a las experiencias relacionales de fracaso previas, los niños y adolescentes con este estilo de apego intentan evitar relaciones en las que haya que implicarse emocionalmente para no ser rechazados y/o abandonados. Y cuando comienzan a tener una relación más íntima o con cierta dependencia pueden enfrentarse a los sentimientos que conllevan de forma fría, racional o distante (Barudy \& Dantagnan, 2009). Según estos autores, en el espacio terapéutico los niños y adolescentes con este estilo de apego tienen una gran resistencia a implicarse en la terapia, ya que la relación terapéutica es vivida con ansiedad por la amenaza que supone salir de su aislamiento emocional. Una vez iniciada la terapia pueden surgir resistencias como no acudir a la sesión, negarse a hablar o mostrar una actitud de rechazo hacia el terapeuta.

Es posible intuir que por el abandono de la madre, María haya tenido dificultades en establecer un apego seguro. Sin embargo, tampoco podemos afirmarlo con rotundidad porque carecemos de la información necesaria. Además, hay investigaciones (Fonagy, 1999) que indican que las experiencias traumáticas pueden modificar estilos de apego, por lo que quizás la enfermedad podría haber influido o empeorado la situación. En un estudio realizado con adultos dializados, se encontró que casi la totalidad de los pacientes presentaban un apego inseguro, por lo que los autores establecen una relación entre la enfermedad crónica y la modificación de los patrones vinculares (Pía, Garrido, Fuentes, Guzmán, \& Lizano, 2009).

La actitud de María hacia mí, compatible también con un tipo de apego inseguro ansioso, donde la actitud hacia los demás es ambivalente, por un lado los necesitan y dependen de ellos, pero por otro, están enfadados y los rechazan (Corem, Snir, \& Regev, 2015), despertaba en mí diferentes sensaciones. Una de ellas era la incertidumbre. Incertidumbre ante no saber cómo iba a recibirme, ante no saber si me iba a rechazar, o si querría trabajar.... Sin duda, esta inseguridad y cierta negatividad ante 
el proceso tuvieron una influencia negativa en la relación terapéutica que es esencial en las primeras etapas de la terapia (Navia \& Arias, 2012).

En la siguiente sesión ( $n^{\circ}$ 9) cometí el error de llegar tarde. Al entrar en la sala vi que estaba haciendo los deberes y no me saludó ni me miró. El personal médico comentó que había preguntado por mí antes de comenzar con los deberes, pero ahora que ya estaba allí, había decidido ignorarme. Me disculpé por mi retraso e intenté por diferentes medios captar su atención, le propuse ayudarla con los deberes, hacer alguna actividad divertida, me interesé por su estado de ánimo y por su enfado... pero no obtuve respuesta. No levantaba la cabeza del cuaderno. El personal médico presente en la escena comenzó a presionar a María para que trabajara, a lo que ella reaccionó con malas contestaciones, enfrentamientos y miradas de odio. En ese momento, intenté mediar y quitarle importancia a su rechazo, pero tras un tiempo de estar allí y no conseguir nada le pregunté si quería que me fuera y me respondió que sí, así que finalmente me fui antes de que terminara nuestro tiempo.

“¿Por qué la semana anterior esperaste y en esta sesión decidiste marcharte?” Me preguntó mi supervisora en nuestro encuentro. "Porque no veía intenciones de cambiar en ella, la vi muy cerrada y me pidió que me fuera”. Respondí. ¿Y no crees que estás poniendo la culpa en ella, que es tu paciente? ¿Qué fue lo que te pasó a ti?; Comprendí entonces que en esa sesión primó una atención hacia mí, en vez de estar plenamente con ella. La contratrasferencia actuaba, alterando la reacción entre ambas. Según Herman (2004) las reacciones adversas del terapeuta deben ser comprendidas y controladas para no perturbar la alianza terapéutica con el paciente, especialmente en el trabajo de las personas que han sufrido eventos traumáticos, pues el trauma destroza su capacidad para crear una relación de confianza. Esto tiene un evidente impacto en el terapeuta y por tanto es de esperar que surjan dificultades para crear una alianza terapéutica que funcione.

Tras mi supervisión comprendí mis errores, llegué a entender que necesitaba que la escucharan, y que el llegar tarde o no acudir durante las vacaciones de Navidad pudieran despertar en ella sentimientos de abandono, lo que se traducía en rechazos hacia mí. De nuevo la literatura me confirmaba este hecho ya que, según Valentín Escudero, experto en terapias familiares, cuando se trabaja con niños y niñas que han sufrido trauma relacional es fundamental entender cómo los sentimientos de traición y abandono afectan a la relación terapéutica. En muchas ocasiones esta relación comienza probando al terapeuta y su lealtad, porque deben estar seguros de que el terapeuta no les volverá a traumatizar con un nuevo abandono o traición (Escudero \& Friedlander, 2017).

Durante diferentes etapas en el proceso sentí como María intentaba ponerme a prueba. Por ejemplo cuando tras la realización de los retratos me pidió que hiciera un vídeo cuando llegara a casa mostrando cómo colgaba su dibujo en mi casa y cómo se lo enseñaba a mi hijo. Yo sentí su petición como una muestra de su necesidad de saber que realmente era importante para mí. Y me hizo cuestionarme cómo debía responder, ¿debo hacerlo o debo demostrarle que estoy aquí de otra forma?, ¿Cómo hacer para no decepcionarla? Los materiales que llevaba a la sesión también se convirtieron en una forma de ponerme a prueba, llegando a enfadarse conmigo si se me olvidaba llevar algo, lo que provocaba en mí cierta tensión. Tenía una sensación de "no debes volver a cometer errores", una gran conexión con lo negativo, un sentimiento de estar a prueba y de intentar no equivocarme de nuevo, que también me conectaba con sentimientos de culpa. De nuevo Herman, nos habla de la transferen- 
cia traumática y la necesidad del paciente de que el terapeuta sea perfecto, unas expectativas idealizadas, que cuando el terapeuta no consigue - algo inevitable- puede provocar la ira de la paciente (2004).

En nuestra siguiente sesión tras la supervisión, me sentí más fuerte y preparada para afrontar la situación y sostener su enfado. Como era de esperar, su acogida fue fría, no me habló ni me miró. Tras un tiempo de paciencia y con una mayor disposición hacia ella, reconociendo su enfado, finalmente cambió de actitud, me sonrió y comenzó a trabajar como si no hubiera pasado nada, tocando mi barriguita y preguntándome por el bebé. En esta décima sesión terminó una caja contendora de emociones, que decidió dejar vacía y utilizar únicamente de adorno, y preparamos una lista de materiales necesarios para las actividades que quería realizar en las siguientes sesiones, entre las que estaba hacer una marioneta de calcetín.

En la siguiente sesión $\left(\mathrm{n}^{\circ} 11\right)$, María me recibió con una sonrisa y un "te echaba de menos". Trabajamos en la construcción de la marioneta calcetín, actividad que ella ya había realizado anteriormente en otro contexto. Quizás por ello, María disfrutó durante el proceso de realización de su marioneta Jake, a quien definió como un poco antipático cuando estaba de malas (Ver figura 4).

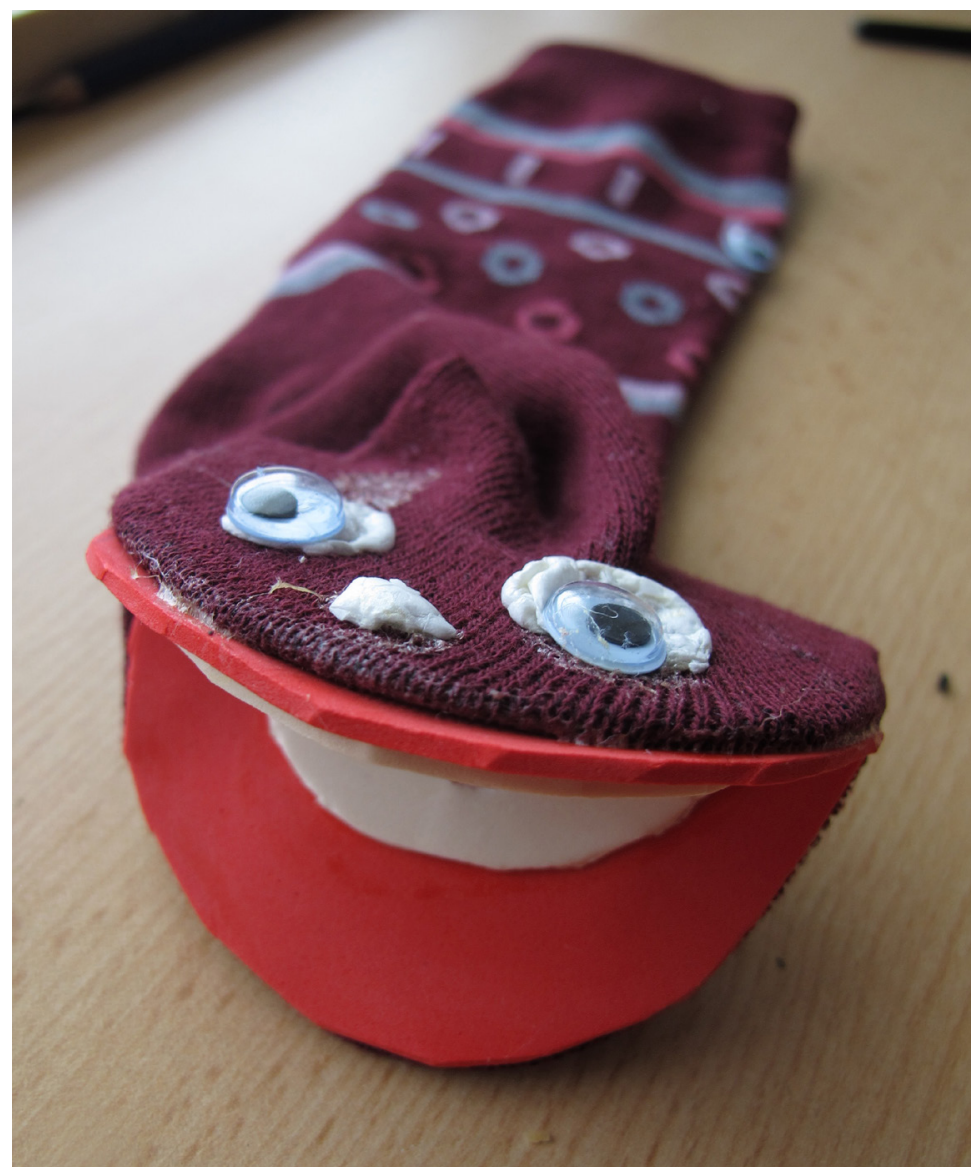

Figura 4. "Jake" 
Al comienzo de la intervención establecimos que las obras las conservaría yo hasta la finalización del proceso, sin embargo, en esta ocasión insistió en quedarse con Jake, a quien parecía bastante apegada. También quiso entonces quedarse con la caja contenedor de emociones de la semana anterior para guardar a su marioneta. Normalmente no se mostraba apegada a las obras, ni se oponía a que las guardara yo como acordamos al principio. En general, solía mostrar un gran entusiasmo al principio por descubrir los materiales y comenzar la creación, para después aparecer la pérdida de interés en lo que estaba haciendo, y el abandono en cuanto surgía la dificultad o un trabajo repetitivo, llegando a terminar pocas de ellas. Era como si con el proceso y las obras estableciera también relaciones ambivalentes. Según un estudio publicado en Arts in Physchotherapy en el que se analiza el vínculo del paciente con el arteterapeuta y su relación con el proceso creativo, se sugiere que aquellas personas con un patrón de apego inseguro evitativo también percibirán el proceso creativo como una experiencia negativa. Cuanto mayor es el grado de evitación, mayor será la actitud negativa hacia el proceso creativo (Corem et al., 2015). Sin duda, este hecho es un punto interesante a estudiar dentro del campo del arteterapia y que merecería una mayor investigación.

La sesión 12 transcurrió en la planta hospitalaria en lugar de la sala de hemodiálisis por un ingreso de María, quien se mostró sorprendida y contenta por verme allí. Como se encontraba bien, pudimos trabajar de nuevo en la construcción de marionetas de calcetín, con las que posteriormente interactuamos. Después, le invité a crear una historia a través del "Six part story method"5 tal y como estaba previsto inicialmente en el diseño del proyecto, pero rechazó la propuesta diciendo que se encontraba mal, malestar que se le pasó en cuanto cambiamos de actividad. Por mi parte, de nuevo empezaron a surgir sentimientos de frustración. Sentía que el proceso no avanzaba, al menos al ritmo que yo deseaba, y me sentía como si simplemente estuviera llevando a cabo un taller de manualidades.

En la siguiente sesión ( $\left.n^{\circ} 13\right)$, ya en nuestro contexto habitual, María decidió crear un escenario de cartón para las marionetas. Trabajamos juntas en el proyecto, pero su actitud hacia mí en esa sesión fue algo hostil, parecía enfadada, me hablaba dándome órdenes y sin pedir nada por favor ni de buenas formas. Le hice ver este hecho, pero su respuesta ante esto fue "no me des la "murga", yo soy así y me tienes que aguantar asi". Esta actitud y contestaciones eran frecuentes con el personal médico y de enfermería, pero hasta ese momento no las había tenido conmigo. Intenté hacerle ver las "ventajas" de tratar bien a las personas, pero se cerró y me llegó a decir que le había dicho que era "mala". Le expliqué que yo no pensaba que fuera "mala" sino que me estaba hablando mal en ese momento. Pero su enfado fue a más, negándose a terminar la actividad, recoger, limpiar su mesa y a despedirse de mí. Además, quiso guardar el escenario en su taquilla, pero por falta de espacio finalmente me lo llevé yo, junto con los materiales y el resto de obras, ante lo que se enfadó aún más.

En la siguiente sesión $\left(\mathrm{n}^{\circ} 14\right)$ su recibimiento fue frío, sin hablarme ni mirarme de nuevo. Seguía enfadada. Mi actitud esta vez fue de acogida, de espera y decidí estar allí y no irme durante el tiempo que durara la sesión. Así se lo expliqué y tras varios intentos en vano de hablar con ella y motivarla le dije que si quería trabajar, yo estaría allí. Con la intención de captar su atención y volver a vincular a través del retrato, comencé a dibujarla en su cama, mientras ella me miraba con curiosidad de vez en cuando para ver qué hacía (ver figura 5).

Método de creación de historias en seis partes desarrollado por el dramaterapeuta israelí Mooli Lahad. 


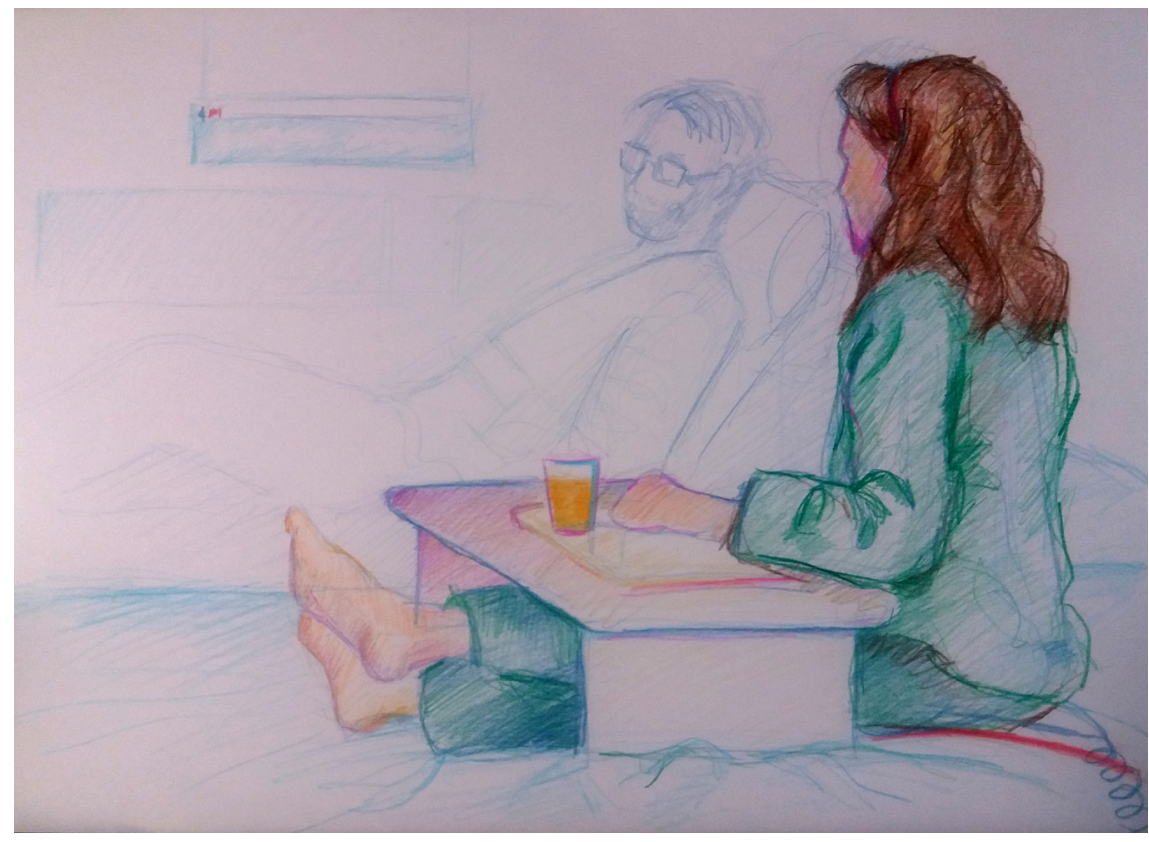

Figura 5. "El rechazo" Obra y título de la autora.

La hora de la sesión se hizo larga para mí, aunque dibujar ayudó a calmar mi ansiedad. Cuando pasó la hora de la sesión y comencé a despedirme quiso empezar a trabajar, pero su actitud hostil proseguía, sin mirarme ni hablarme, limitándose a coger materiales para algo que deduje debía ser un trabajo para su clase de inglés. Aunque le pregunté, se negó a hablarme y decidí poner el límite ahí y despedirme. En uno de los encuentros con la doctora me comentó que tenía días así, y que esta actitud no la tenía sólo conmigo, pero esto no me hizo sentir mejor, los sentimientos que despertaba en mí eran encontrados, por un lado, sabía que debía estar ahí, pero por otro me preguntaba ¿cuánto debo aguantar? ¿Debo poner límites? ¿Cuál es la actitud correcta? Si abandonaba la sesión, abandonaba también a mi paciente. Pero por otro lado, permanecer allí también puede resultar algo invasivo cuando la otra persona no desea tu presencia o trabajar en ese momento.

Esta sesión me hizo sentir que no habíamos conseguido nada durante el proceso y fue el tema central de mi siguiente supervisión, en la que la pregunta principal fue: ¿qué es lo que sí habéis conseguido?, a lo que yo no supe qué responder. De nuevo esta supervisión y leer sobre la contratransferencia en casos de niños y niñas con problemas de apego me tranquilizó y ayudó a entender el proceso. Rygaard, autor de $E l$ niño abandonado, una gran referencia en trastornos de apego, lo denomina "estadio de la depresión por el contacto con la realidad". En este estadio,

el supervisado comienza a pensar que todos los esfuerzos son en vano. En verdad, lo que ensaya sólo parece agravar las cosas. Asume inconscientemente los mecanismos de defensa del niño sin saber qué pasa (negación, rechazo, disociación, identificación proyectiva, baja autoestima, incompetencia, desistimiento, etcétera) (Rygaard, 2008, p. 278). 
Según el autor, en esta etapa es frecuente que el terapeuta, educador o padres adoptivos que están tratando con el menor desistan y abandonen, y destaca la importancia de no usar el comportamiento del niño en la explicación que se le da a éste sobre la finalización de esta relación. Si se supera esta fase de frustración, se puede dejar de poner el foco en las deficiencias del niño para realmente ayudar al niño a desarrollarse. El problema era que aunque yo me encontraba plenamente en esta fase de “depresión”, y quería llegar a superarla, me veía ya obligada a comenzar un proceso de cierre debido a mi embarazo. ¿Cómo afrontar el proceso de cierre en esta situación? ¿Cómo cerrar sin que ella viva de nuevo esto como un abandono, un abandono causado además por una maternidad? ¿Cómo cerrar el proceso si no me habla?

\section{3. Última fase: proceso de cierre}

El proceso de cierre fue más corto de lo que habría querido por cambios de horarios del hospital que hicieron que pudiéramos encontrarnos únicamente una vez cada dos semanas, en lugar de todas las semanas. Una de mis mayores preocupaciones era que María sintiera que el proceso se acababa por su actitud negativa hacia mí, porque a pesar de ser algo que yo no le había dicho, sí lo había oído por parte del personal médico. En la siguiente sesión (nº15), llegué con la intención de hablarle a María sobre el proceso de cierre. La incertidumbre ante su reacción y acogida era ya constante en cada sesión, pero para mi sorpresa María me recibió sonriente, contenta y me preguntó cómo iba mi embarazo. Aproveché su interés y disposición a escuchar para explicarle que debido a la próxima llegada del bebé, debíamos comenzar un proceso de cierre y despedida. Le pregunté si tenía alguna pregunta o si me quería decir cómo se sentía al respecto, pero su respuesta simplemente fue "estoy harta de hablar, quiero ver los materiales nuevos y hacer algo”. Decidió continuar con una actividad que habíamos comenzado la semana anterior, el escenario de cartón para las marionetas, ante lo que tuve que confesarle que lamentablemente había desaparecido, porque la caja no estaba con las cosas de arteterapia, como yo lo dejé la semana anterior. Entonces su enfado se volvió a disparar, dejó de hablarme y comenzó a mostrar una actitud hostil hacia mí, diciendo que no quería que me sentara en la silla, porque era de su tío. A pesar de su enfado comenzó a realizar una flor con goma EVA, pero se cansó pronto y empezó a jugar con el pegamento, sacando todo su contenido y fabricando una bola pegajosa. Le hice ver que probablemente no era lo mejor que podía hacer con el pegamento, pero me ignoró. Después de esto por primera vez llegó a reconocer que estaba enfadada conmigo, pero no quiso decirme porqué. Al final de esta sesión, previa a las vacaciones de Semana Santa, le propuse que escribiera sobre su enfado, pero me dijo que no lo haría y que a la vuelta seguiría ignorándome. Sentía que María vivía este proceso de cierre como un abandono por mi parte, lo cual se manifestaba a través de su enfado conmigo. Yo le expliqué que volvería, aunque me ignorara, porque así lo habíamos pactado al principio y yo tenía un compromiso con ella, que no iba a dejar de ir porque ella me ignorara, sino porque la fecha del parto se acercaba.

En nuestra penúltima sesión de nuevo su recibimiento fue frío, no quiso hablar ni trabajar. Le pregunté por la carta, pero me dijo que no la había hecho. Intenté comenzar una conversación, le ofrecí los materiales, y tras varios intentos frustrados 
de pronto su actitud cambió cuando le pregunté sobre cómo era la posición correcta de los pétalos de la flor que hizo en la sesión anterior. Entonces quiso buscar en el móvil alguna idea para hacer y encontró unas margaritas de goma EVA, que quiso que hiciéramos juntas, aunque enseguida perdió el interés y de nuevo no terminó la actividad. En esta sesión su relación conmigo fue buena, a pesar de que le expliqué que la siguiente sesión sería la última.

De nuevo por cambios de horario, pruebas médicas y días festivos, nuestro último encuentro se retrasó. Aunque se mostró algo indiferente ante mi llegada, al final se mostró cordial. En esta sesión decidió hacer diferentes obras, sin llegar a terminar ninguna, comenzó un bote para lápices con cartón, sobre el cartón sobrante pintó un paisaje, también decoró unos palos, trabajó sobre las margaritas de la sesión anterior, fabricó slime ${ }^{6}$ con pegamento y pintura (ver figura 6) y me pidió materiales para continuar haciendo manualidades cuando me fuera.

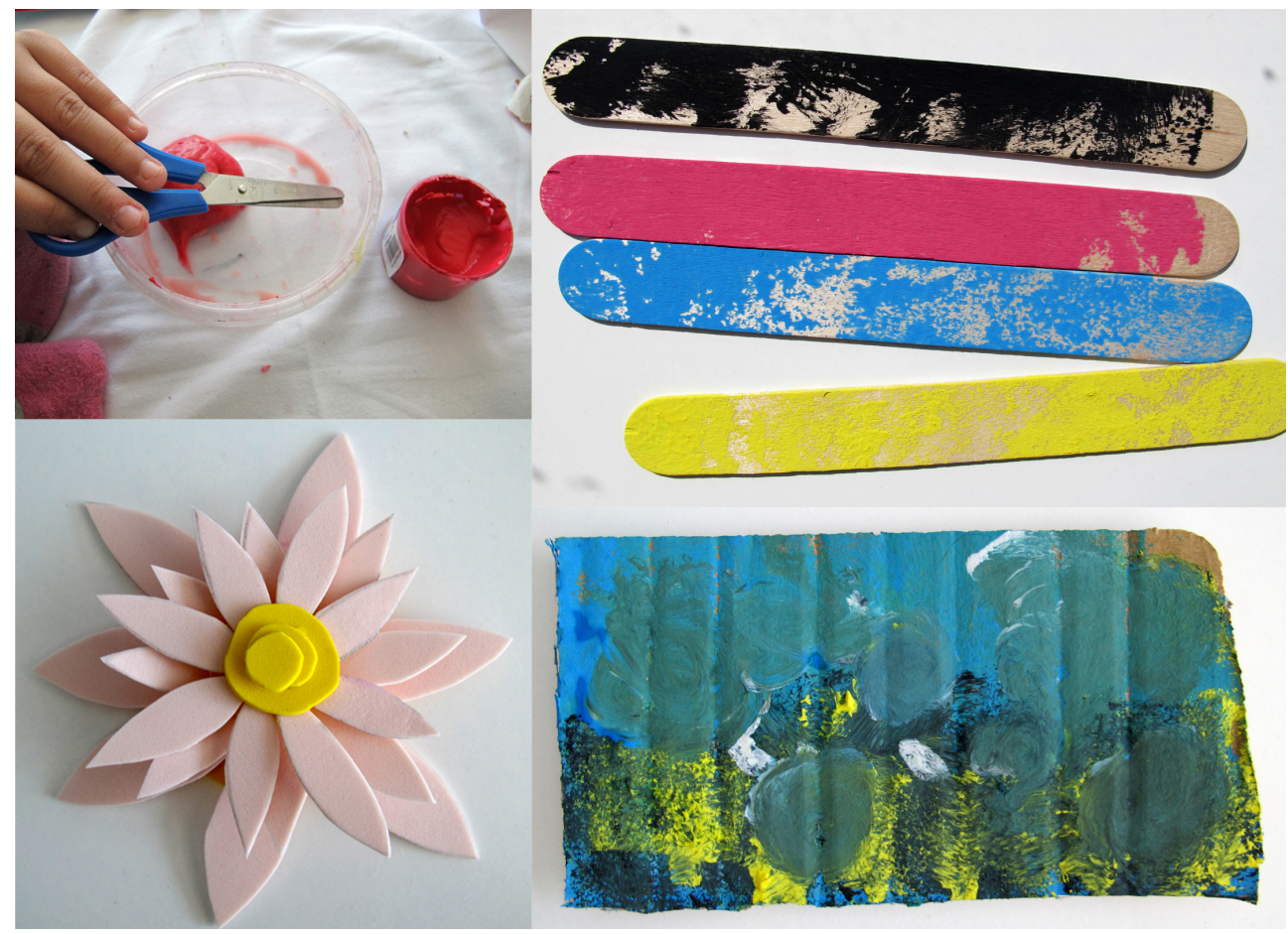

Figura 6. Obras realizadas en la última sesión

Al final de la sesión le regalé un detalle que había hecho yo misma para ella con pasta de sal, revisamos sus trabajos y realicé una devolución positiva sobre los logros que, a pesar de las dificultades, había conseguido. Se mostró triste porque se terminara el proceso y con ganas de continuar más adelante, algo que quizás pueda ser posible, pero que no le pude garantizar. Pero principalmente, en esta última sesión, le agradecí haberme ayudado a crecer y a mejorar en esta profesión, a través de un proceso continuo de aprendizaje.

6 Masa moldeable y pegajosa cuya versión casera se ha vuelto muy popular entre los jóvenes, quienes consultan y publican en redes sociales vídeos sobre su realización. 


\section{Conclusiones}

A través de este relato se ha dado visibilidad a las dudas, errores y emociones vividas por parte de la arteterapeuta en este caso que podemos considerar fallido, pero a partir del cual se pueden extraer aprendizajes y reflexiones.

Una de las primeras conclusiones extraída de esta experiencia es la necesidad de un espacio para el arteterapia dentro del ámbito hospitalario. Hemos visto como la intervención psicológica dentro del hospital se centraba en preparar a la persona para el proceso que va a suponer pasar por un trasplante, siendo imposible por la carencia de recursos, abarcar otros temas que son también fundamentales en el desarrollo emocional y personal de los pacientes pediátricos. La mirada integral del arteterapia, centrándose en todos los aspectos de la persona, y no únicamente en la enfermedad, complementa y apoya el servicio del hospital.

Sin embargo, también debemos ser realistas y alejarnos de las expectativas e idealizaciones que podamos tener al comenzar un caso. En primer lugar hay que ser conscientes de las limitaciones que no dependen directamente de nosotros, como las dificultades integrarse plenamente con el equipo médico o los cambios de encuadre externo. Pero por otro lado, hay que prestar atención a las limitaciones internas, ser conscientes de nuestras capacidades, así como ser realistas a la hora de establecer los objetivos terapéuticos, especialmente cuando se están abordando experiencias traumáticas como una enfermedad crónica y la pérdida de una de las figuras de referencia. A través de las sesiones el propósito era que María pudiera expresar el miedo, la angustia y el enfado, pero para ello necesitaba sentir un vínculo fuerte y seguro, que no es fácil construir y para lo cual se hubieran necesitado un mayor número de sesiones.

Por otro lado, también ha existido un desajuste en los objetivos terapéuticos, entre el ritmo al que progresaba María en su proceso, con sus pequeños avances y resistencias y mi ansiedad por alcanzar unos objetivos, quizás por mi deseo de obtener unos resultados interesantes para la investigación. Por ello, otro de los aprendizajes o conclusiones que hemos podido ver a lo largo del relato es la necesidad de escucha y de adecuación al ritmo del paciente. Pero esa escucha también debe ser interna, prestando muchísima atención a la contratransferencia y a la situación personal del terapeuta. Quizás, mi estado físico y emocional por el embarazo influyera también en la relación terapéutica. Quizás simplemente el contacto con ella y su enfermedad, así como ver a tantos niños y niñas enfermos por los pasillos del hospital, me recordaban la vulnerabilidad de la vida, cuando estaba creando una vida dentro. Imaginarme el abandono de su madre, ver como una niña llena de energía depende de una máquina casi a diario, la incertidumbre sobre su futuro trasplante, el miedo a la operación... Todo ello me llevó a identificarme con sus sentimientos, sensación de indefensión y emociones. Algo totalmente contraproducente para el proceso terapéutico.

Por otro lado, el embarazo a mi modo de ver tuvo una gran influencia en el desarrollo de la terapia, pues anunciaba y evidenciaba una futura separación. Su rechazo parecía decir: ¿Para qué dedicarte mi tiempo si de todas formas te vas a marchar? Me resultaba difícil aceptar este rechazo y gestionar mis emociones, lo que provocó que me fijara más en todas las dificultades que en los avances de ambas. Sin duda, en todo este proceso ha sido fundamental el trabajo supervisión, que me ha ayudado a manejar la contratransferencia y a resituar cuáles eran los objetivos, las reglas y límites del contrato de terapia. 
Por otro lado, destaco también la necesidad de la terapia personal, siempre importante pero esencial en casos de trauma y trastornos de apego, que sacarán a la luz la propia historia de trauma y apego del terapeuta.

En resumen, tanto la terapia personal como la supervisión es una parte fundamental para poder ayudar realmente a las personas con las que queremos trabajar, especialmente en los casos de trauma, ya que como dice Herman, "al igual que no hay ningún superviviente que pueda recuperarse solo, tampoco hay ningún terapeuta que pueda trabajar solo con el trauma" (2004, p. 223).

\section{Referencias}

Ainsworth, M. (1978), Patterns of attachment. Citado en: Barudy, J., \& Dantagnan, M. (2009). Los buenos tratos a la infancia. Parentalidad, apego y resiliencia. Barcelona: Gedisa.

Barrantes, T. (2016). Arteterapia en una unidad de diálisis pediátrica. Arteterapia. Papeles de Arteterapia Y Educación Artística Para La Inclusión Social, 11(0), 309-324. https://doi. org/10.5209/ARTE.54134

Barudy, J., \& Dantagnan, M. (2009). Los buenos tratos a la infancia. Parentalidad, apego y resiliencia. Barcelona: Gedisa.

Bowlby, J. (1998). El apego y la pérdida (Vol. 1) (Psicología). Barcelona: Paidós.

Corem, S., Snir, S., \& Regev, D. (2015). Patients ' attachment to therapists in art therapy simulation and their reactions to the experience of using art materials. The Arts in Psychotherapy, 45, 11-17. https://doi.org/10.1016/j.aip.2015.04.006

Escudero, V., \& Friedlander, M. L. (2017). Child Maltreatment: Creating Therapeutic Alliances with Survivors of Relational Trauma. In Therapeutic Alliances with Families, Focused Issues in Family Therapy (pp. 99-126). Cham: Springer International Publishing AG.

Feliu, J., \& Lajeunesse, S. (2007). Nuevas formas literarias para las ciencias sociales: el caso de la autoetnografía. Athenea Digital, 12(otoño), 262-271. Retrieved from https://ddd. uab.cat/pub/athdig/15788946n12/15788946n12p262.pdf

Fonagy, P. (1999). Persistencias Transgeneracionales Del Apego: Una Nueva Teoria. Aperturas Psicoanalíticas, 3, 1-13. https://doi.org/10.1021/ma200256v

Guzmán, V. M., Torres, J., Plascencia, A., Castellanos, J. de la L., \& Quintanilla, R. (2011). Cultura hospitalaria: y el proceso narrativo en el niño enfermo. Estudios Sobre Las Culturas Contemporáneas, XVII(33), 23-44. Retrieved from http://dialnet.unirioja.es/ servlet/articulo? codigo $=3765530 \&$ info $=$ resumen\&idioma $=\mathrm{ENG}$

Herman, J. (2004). Trauma y Recuperación. Cómo superar las consecuencias de la violencia. Pozuelo de Alarcón (Madrid): Espasa Calpe.

Johnson, A. (2008). Art therapy and pediatric hemodialysis: creating therapeutic space in an open unit medical setting. Retrieved from http://spectrum.library.concordia.ca/976189/

Laplanche, J., \& Pontalis, J.-B. (2004). Diccionario de Psicoanálisis. Buenos Aires, Barcelona, México: Paidós.

Levine, P. A., \& Kline, M. (2016). El trauma visto por los niños. Barcelona: Eleftheria.

Malchiodi, C. A. (1999). Medical Art Therapy with Children. London and Philadelphia: Jessica Kingsley Publishers.

Navia, C. E., \& Arias, E. M. (2012). Alianza terapéutica y su relación con las variables de apego del terapeuta y del consultante. Universitas Psychologica, 11(3), 885-894.

Nishida, M., \& Strobino, J. (2005). Art Therapy with a Hemodialysis Patient: A Case Analysis. Art Therapy: Journal of the American Art Therapy Association, 22(4), 221-226. 
Payne, M. (2002). Terapia Narrativa. Una introducción para profesionales. Barcelona: Paidós.

Pía, M., Garrido, L., Fuentes, M., Guzmán, M., \& Lizano, M. (2009). Estudio de los estilos de apego adulto en un grupo de pacientes con insuficiencia renal crónica terminal. Universitas Psychologica, 8(2), 413-422.

Rygaard, N. P. (2008). El niño abandonado. Guía para el tratamiento de los trastornos de apego. Barcelona: Gedisa.

Santos Sánchez-Guzmán, E. M. (2013). Reflexiones en torno a la investigación en arteterapia. Red Visual, 19, 17-29. Retrieved from http://www.redvisual.net/pdf/19/redvisual19_02_ santos.pdf

Schreibman, R. C. (2013). Art Therapy and Hemodialysis Coping Cratively With Kidney Failure. En Malchiodi, C. A. (Ed.), Art Therapy and Health Care. (pp. 212-224). London. The Guilford Press.

Van der Kolk, B. (2015). El cuerpo lleva la cuenta. Cerebro, mente y cuerpo en la superación del trauma. Barcelona: Eleftheria.

Weldt, C. (2003) Patients' Responses to a Drawing Exprerience Hemodialysis unit: A Step Towards Healing. Art Therapy: Journal of the AATA. 20(2) pp. 92-99. 